\section{Johannes Reichmayr (Hrsg.): Ethnopsychoanalyse revisited. Gegenübertragung in transkulturellen und postkolonialen Kontexten}

(Psychosozial-Verlag, Giessen, 2016)

Vera Hirt (Zürich)

Ein schönes Buch, welches auf dem Umschlag mit der lebendigen Bilderwand aus der Küche der drei Mitbegründer der Ethnopsychoanalyse Paul Parin, Goldy Parin-Matthèy und Fritz Morgenthaler dazu einlädt, die Gegenübertragung in transkulturellen und postkolonialen Kontexten in den Fokus zu nehmen. Die interdisziplinäre Auswahl der Texte von hoher Intensität und Dichte zu lesen, freute mich jeden Abend von Neuem. Denn da stehen verschiedene Denkarten, Arbeitsund Lebenswelten sinnig nebeneinander, die das Fremde zum Thema machen, ohne die eigene Perspektive als unmittelbar darauf antwortendes Subjekt aus den Augen zu verlieren. Die Gegenübertragung rückt ins Zentrum der Betrachtung, wo es darum geht, eigene Irritationen in der Begegnung mit dem fremden Anderen als solche wahrzunehmen, um stereotype Abwehrreaktionen wie Exotisierung, damit innere Distanzierung, Bewunderung, Entwertung oder phobischen Rückzug zu vermeiden.

Der Herausgeber Johannes Reichmayr spannt den Bogen von Afrika über China, ins Gefängnis, zum Ultra-Fussballfan über das dritte soziale Geschlech der Muxés in Mexiko zur Diskussion über Kolonialismus und Postkolonialismus sowie weiteren Begriffsklärungen im Umfeld der Ethnologie, Volkskunde und Kulturanthropologie bis zu aktuellen ethnopsychoanalytischen Fragestellungen im Bereich der Migration. Dies alles geschieht in einem Sprachduktus des persönlichen Engagements der Autor_innen, fast wie wenn die Gespräche mit Paul Parin nie geendet hätten. Erst im letzten Teil des Buches wird abrupt deutlich, dass die Geschichte des «Glückspilzes», zu dessen 100. Geburtstag dieses Werk der Anlass ist, zu Ende gegangen ist. Die Sprache wechselt da streckenweise in den Modus des detaillierten bis akribischen Beleuchtens der Fakten im langen Leben von Paul Parin und Goldy Parin-Matthèy. Das Paar war für die Entwicklung der Ethnopsychoanalyse prägend, was die umfassende, zukunftsgerichtete Bibliografie widerspiegelt und zu weiteren Auseinandersetzungen inspiriert.
Beispielsweise drängt sich aus aktuellem Anlass im Zusammenhang mit der immensen Flüchtlingswelle die Debatte auf, wie der Retraumatisierung im Asylverfahren, welches primär juristisch geführt wird, vorgebeugt werden kann (Kronsteiner). Die Betrachtung von Kultur ist immer von der Position und Mach des Betrachters und dessen Perspektive abhängig (Nadig). Ohne diese zu hinterfragen und zu reflektieren, verkommen Irritationen in der Begegnung mit Asylsuchenden zu juristischen Auffälligkeiten, welche einerseits den kulturellen Habitus wie auch die Virulenz des Traumatischen nicht zu berücksichtigen vermögen. Je häufiger Irritationen in einem solchen Verfahren auftreten, je weniger wird geglaubt. Das Trauma setzt sich erneut in Szene, was Kronsteiner unter dem Begriff der PsychoTraumaDynamik zusammenfasst.

An diesem Beispiel wird klar, wie wichtig Deutungswerkstätten (Nadig), das Kitchen Seminar aus der Cultural Psychology oder auf der Seite der dazugekommenen Fremden der "third space" als Orte der Reflektion und des Verstehens sind. Entsprechend weisen einige Autor_innen auf diese Instrumente für die Bearbeitung der Gegenübertragung im Gruppenaustausch, ähnlich wie in der Trauminterpretation nach Morgenthaler, hin. Der folgende Wandel in der Fremdwahrnehmung verändert immer auch das Selbstbild. Die Subjektivität zu zeigen, ist erwünscht.

Wir tun also gut daran, das Eigene auch immer wieder als fremd einzustufen, um unvoreingenommen genau hinzuschauen. Die «cure de la parole» basiert gerade auf dem Entdecken der Mehrdeutigkeiten, welche gezwungenermassen im Ergründen und Erfühlen des Fremden angelegt sind. Sprachliche Begrenzungen lassen sich durch das Einbeziehen der anderen Muttersprache, aber auch der eigenen, aufweichen. Das fordert uns Psychoanalytiker_innen heraus, eine verstärkte Ambiguitätstoleranz zu entwickeln.

Jenes Zulassen von mehrdeutigem Sinn ist beispielsweise im alltäglichen Leben in nordafrikanischen Ländern Teil der Kultur. Becker plädiert für eine erneuerte Ethnopsychoanalyse, worin die Psychoanalyse selbst als Kulturprodukt verstanden und hinterfragt werden soll. Ein differenzierter Fragekatalog (ebd., S. 338f.) ergänzt die kritische Haltung gegenüber postkolonialistischen Sichtweisen, die in diesem Werk mehrfach zur Sprache kommen. Frantz Fanon (1925-1961), unter anderem tätig als Chefarzt in der Psychiatrischen Klinik nahe Algier, untersuchte insbesondere nördlich der Sahara die Phänomene von Unterdrückung und Autonomie bei den Widerstandskämpfern, worauf Bird-Pollan in einem interessanten Diskurs mithilfe der Hegel'schen Herr-Knecht-Dialektik Bezug nimmt. In den Zeiten des Neokolonialismus zeigen Analysen dieser Art eine vertiefte, dif- 
ferenzierte Sicht auf wirtschaftlich bedingte Ungleichgewichte gerade auf dem Kontinent Afrika, dem faszinierenden Ort für Paul Parin. 